\title{
EFEITOS DE ALGUMAS CARACTERÍSTICAS DO SOLO NA \\ RESPOSTA DA PLANTA A DOSES DE HERBICIDAS
}

\author{
E. M. Paulo1 \\ J.A. Jorge 2,5 \\ F. B. Arruda3,5 \\ F.R.A. Patrício 4 \\ 1 Pesquisador Científico do Instituto \\ Agronômico, Divisao de Estações \\ Experimentais. Caixa Postal 28, \\ 13001 - Campin as, SP. \\ 2 Pesquisador Científico do Instituto \\ Ag ron ômi co, Se ção de Pe do $\log$ ia. \\ 3 Pesquisador Científico do Instituto \\ Agronômico, Seção de Irrigação. \\ 5 Engenh ei ra Agrô no ma, CATI. \\ Bo ls is ta do CN Pq.
}

\begin{abstract}
RESUMO
Foram estudados em casa de vegetação o tempo de sobre vivência de oito espécies olerícolas a aplic ação de atrazina nas doses correspondentes a 1,8 e $3,2 \mathrm{~kg} / \mathrm{ha}$, e de diuron nas doses de 1,2 e $2,0 \mathrm{~kg} / \mathrm{ha}$, em três tipos de solos ácidos tropicais. Os resultados mostraram alta correlação linear entre o tempo médio de vida das plântulas com teores de matéria orgânica, capacidade de troca catiônica (CTC) efetiva e $\mathrm{pH}$ do solo; e baixas cor relações com teores de argila mais silte. Os resultados indicam ser mais adequado tomar como base a característica CTC do solo em lugar da sua classificação textural para fins de recomendação das doses dos herbicidas.
\end{abstract}

PALA VRAS-CHAVES: atrazina, diuron, espécies olerícolas, matéria organica, CTC.

\section{SUMMARY}

\section{EFFECT OF SOME SOIL CHARACTERIS- TICS ON PLANT RESPONSE TO HERBICIDE DOSIS}

A study was conducted in greenhouse to determine the survival time of eight vegetable plantspecies to soil application of 1,8 and $3,2 \mathrm{~kg} / \mathrm{ha}$ of atrazine, and 1,2 and $2,0 \mathrm{~kg} / \mathrm{ha}$ of diuron, in three tropical soils. High linear correlation was obtained between average survival time and organic matter content, cation exchange capacity (CEC) and soil $\mathrm{pH}$; and low correlation with clay or clay plus silt content. The results lead to the conclusion that it seems more consistent to consider CEC instead of soil texture on dosis recommendation fow both herbicides.

KEYWO RDS: atrazine, diuron, vegetable plant, organic matter, CEC. 


\section{INTRODUÇÃO}

Ao se aplicar um herbicida ao solo parte e adsorvi da aos colóides do solo, parte e perdida por volatilizaçã o, decomposição química, degradação biológica ou lixíviação, ficando o restante na solução do solo para ser absorvido pelas plantas (8). Esta dinâmica dos herbicidas apresenta forte dependência do tipo de solo e dos seus colóides ativos $(1,6,7)$ resultando em maior ou menor adsorção dos herbicidas, o que interferirá na sua ação.

Estudos têm sido conduzidos mostrando a boa correlação da ativida de dos herbicidas com algumas características dos solos de clima temperado, tais como; os teores de argila e mataria orgânica $(5,10,14,15,17)$, o índice de acidez $(5,10,15,17,18)$; e, a capacidade de troca de cations $(10,15,17)$. A interdependência entre essas variáve is tem sido relatada por alguns autores $(15,17)$, o que proporciona um bom suporte para a proposta de recomendação das doses de herbicidas em função dos teores de argila e da matéria orgânica presentes naqueles solos (6).

Nos solos de clima tropical as recomendações têm sido realizadas com base na genérica classificação textural dos solos em arenosos, argilosos e intermediários $(4,7)$ Estes solos, entretanto, ao contra rio dos solos não intemperizados são em sua grande maioria constituídos por minera is de argila de pouca atividade $(2,12$, 13), devendo; a ação dos herbicidas nele aplicados ser regulada também por outros fatores do solo. A alusão a essas variáve is tem sido feita por alguns autores em suas recomendações praticas $(4,7)$ sem, contudo, quantifica-las, provavelmente por carência de informações para as condições tropicais.

O presente trabalho procurou estudar a ação dos herbicidas diuron e atrazina, tradicionalmente usa dos em muitas das grandes culturas brasileiras, relacionando-a a algumas das características dos solos ligadas a adsorção.

\section{MATERIAL E MÉTODO}

O trabalho foi conduzido em casa de vegetação no Centro Experimental de Campinas, no ano de 1984. Foi estudado o tempo médio de sobrevivência de oito hortaliças, em três tipos de solo, e dois herbicidas, com duas doses cada um.

As plantas olerícolas estudadas foram a alface c.v. Brasil 202 (Lactuca sativa L.), o almeirão cv folha-larga (Cichorium intybus L.), a cenoura (Daucus carota L.), a couve-flor (Brassica oleracea L.),

o repolho (Brasssica oleracea $\mathrm{L}$. var. capitata L.), o tomate var. Kada (L ycopersicum esculentun Mill), o crócoles (Brassica oleracea L.) e a rúcula (Eruca sativa L.).

As doses 1,8 e $3,2 \mathrm{~kg} / \mathrm{ha}$ de atrazina e 1,2 e $2,0 \mathrm{~kg} / \mathrm{ha}$ do diuron foram os tratamentos testados. Estas duas doses por produto representam os limites comerciais recomendados para a maioria das culturas anuais.

As caldas herbicidas foram aplicadas a superfície em forma cruzada, sobre caixas de $0,3 \mathrm{~m}^{3}$, com um pulverizador manual, com bico em leque 80.02 e pressão de $2 ; 45 \mathrm{~kg} / \mathrm{cm}^{2}$, mantida constante por injeção direta de $\mathrm{CO} 2$ no tanque do equipamento.

Após a aplicação dos herbicidas, as plantas foram semeadas nas caixas em filete contínuo e a profundidade média de $2,0 \mathrm{~cm}$, distan- 
ciando 5,0 $\mathrm{cm}$ uma fileira das outras. A localização de cada grupo de planta foi sorteada ao acaso. Todos os tratamentos foram repetidos três vezes.

Os solos utilizados foram coletados em Campinas, cujas características são apresentadas no Quadro 1. As análises granulométricas e químicas foram realizadas pela Seção de Pedologia, segundo métodos descritos em Camargo et al. (3) e a capacidade de troca catiônica (CTC) foi calculada indiretamente pela soma de bases (S) mais os teores trocáve is de $\mathrm{Al}+++$ e $\mathrm{H}+$.

\section{RESULTADOS E DISCUSSÃO}

Todas as plantas emergiram seis dias após o plantio, com exceção da cenoura que emergiu no oitavo dia. As plantas no período experimental exibiram sintomas fitotóxicos típicos típicos dos herbicidas do grupo químico das s-triazinas e das urdias substituídas (1).

$\mathrm{O}$ número de dias que cada uma das hortaliças levou para morrer,a contar da sua emergência, 6 apresentado no Quadro 2. Algumas espécies mostraram-se tão sensíveis aos herbicidas estudados que o tem po de vida que apresentaram na dose menor foi praticamente o mesmo que na dose maior.

O tempo médio de vida das oito olerícolas (Quadro 2) foi relacionado aos teores de matéria orgânica, à CTC e ao $\mathrm{pH}$ dos solos do Qua dro 1, sendo representado nas Figuras 1 e 3.

Na Figura 1 verifica-se que no solo contendo $62 \%$ de argila ocor reu o menor tempo de sobrevivência das plantas-testes, independentemente da dose e do produto aplicado. Efeito similar no solo arenoso somente foi conseguido quando se empregaram as doses mais elevadas dos herbicidas. Esses resultados são contraditórios com as recomendações usuais $(4,7)$ as quais indicam que maiores doses dos herbicidas devam sem empregadas em solos com maiores teores de argila.

A discrepância ocorrida possivelmente deve-se ao fato de que as recomendações gerais, como as apresentadas por Hertwig (7),sejam decorrentes de normas utilizadas nas regiões temperadas. Naqueles solos a atividade catiônica pode ser dada preponderantemente pela fração argila que, expressa pela CTC, é muito mais elevada do que as observadas nos solos tropicais, $(2,13)$. Os resultados de Talbert e Fletchall (15) demonstram que quase nenhuma adsorção de simazina e de atrazina foi verificada com a argila caolinita, uma das principais constituintes dos solos tropicais $(12,13)$.

A baixa atividade dos solos en volvidos no presente experimento pode ser constatada pelos baixos valores de CTC no Quadro 1 (5 a 12 meq por $100 \mathrm{~g}$ de solo). Na Figura $2 \quad 6$ demonstrado que a quase totali dade da CTC desses substratos é devida aos seus teores de mataria orgânica; fato também válido para muitos solos paulistas e de cerrado $(11,12,13,16)$. Essas duas características dos solos, a CTC e o teor de matéria orgânica, foram altas, positiva e linearmente correlacionadas com o tempo de sobrevivência das olerícolas (Figura 1), o que indica haver uma maior adsorção dos herbicidas quan to maior for a CTC e o teor de matéria orgânica dos solos. Resulta dos similares foram conseguidos poroutros autores com herbicidas do grupo químico das uréias substituí das e das s-triazinas (5, $10,14,15,17,18)$. 
Quadro 1. Anālise granulomētrica e química dos três solos utilizados.

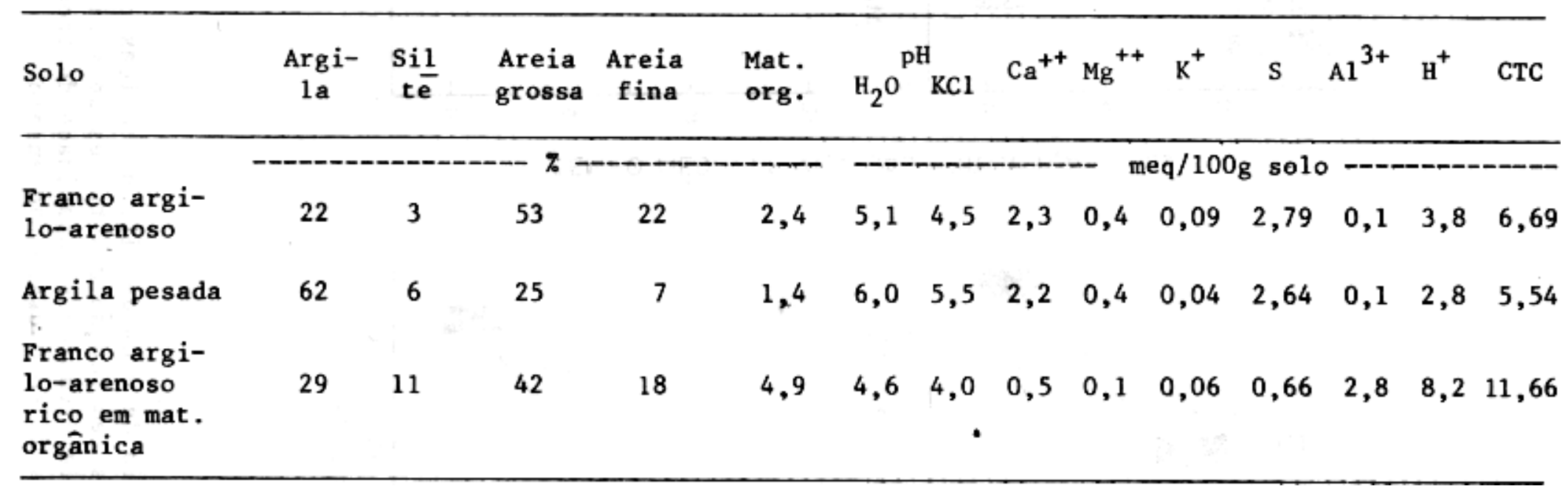



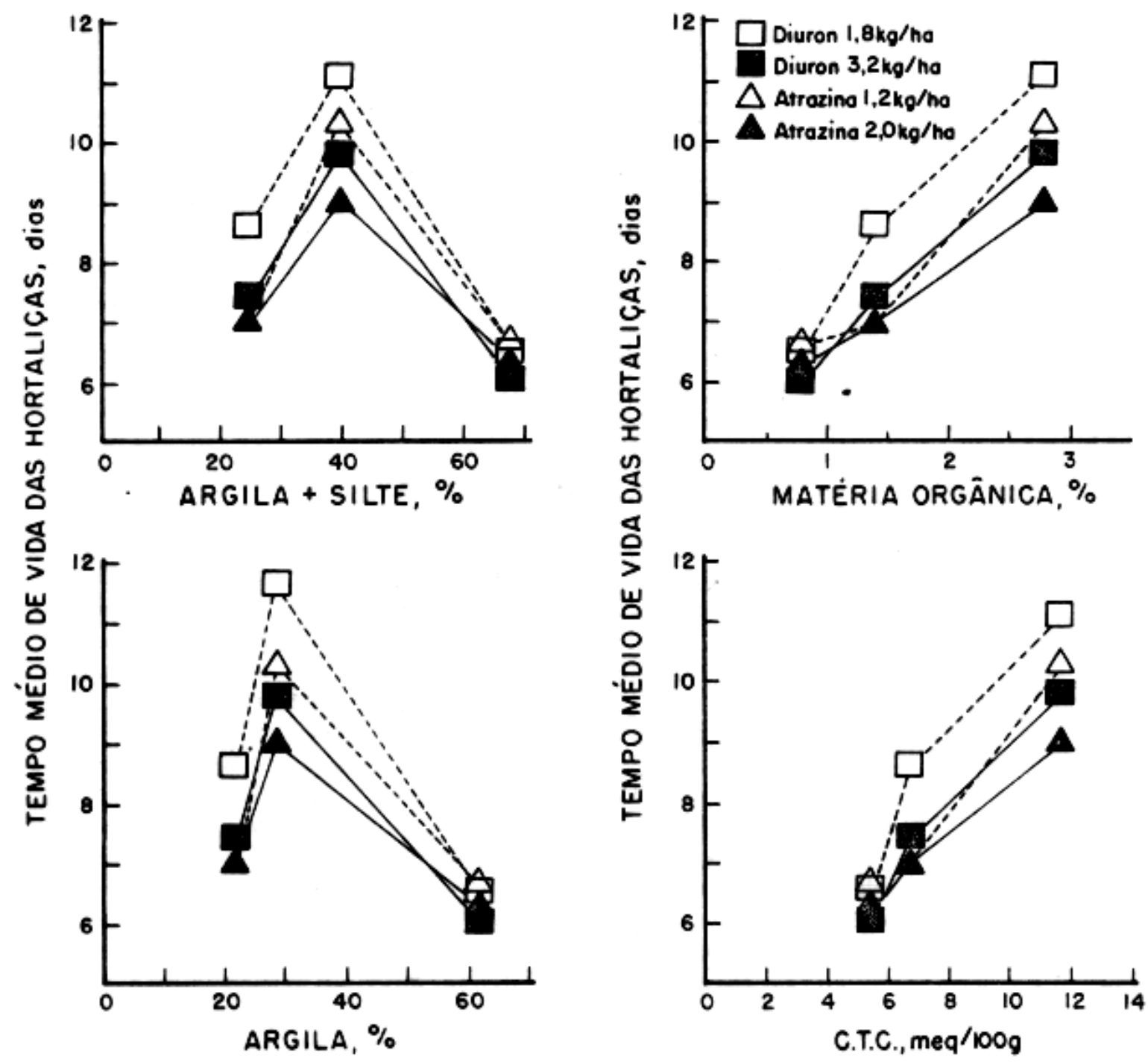

Figura 1. Tempo médio de vida de oito hortaliças para duas doses de dois herbicidas, em função dos teores de argila, argila mais sil te, matéria orgânica e capacidade de troca cationnica (CTC)dos três tipos de solo usados no ensaio. 

Quadro 2. Tempo de sobrevivência desde a emergência para oito olerícolas, em resposta à aplicação de
duas doses de diuron e de atrazina, em três tipos de solos.

\begin{tabular}{|c|c|c|c|c|c|c|}
\hline \multirow[b]{2}{*}{ Culturas } & \multicolumn{3}{|c|}{ Diuron $\operatorname{lg~kg/ha~}$} & \multicolumn{3}{|c|}{ Diuron $2,0 \mathrm{~kg} / \mathrm{ha}$} \\
\hline & $\begin{array}{l}\text { Argila } \\
\text { pesada }\end{array}$ & $\begin{array}{c}\text { Franco } \\
\text { argilo- } \\
\text { arenoso }\end{array}$ & $\begin{array}{l}\text { Fianco } \\
\text { argilo- } \\
\text { arenoso } \\
\text { rico em M.o. }\end{array}$ & $\begin{array}{l}\text { Argila } \\
\text { pesada }\end{array}$ & $\begin{array}{c}\text { Franco } \\
\text { argilo- } \\
\text { arenoso }\end{array}$ & $\begin{array}{c}\text { Franco } \\
\text { argilo- } \\
\text { arenoso } \\
\text { rico em MO }\end{array}$ \\
\hline & \multicolumn{3}{|c|}{ - } & \multicolumn{3}{|c|}{ - dias - } \\
\hline Couve flor & 5 & 4 & 9 & 5 & 5 & 10 \\
\hline Alface & 5 & 6 & 11 & 6 & 6 & 11 \\
\hline Rücula & 5 & 6 & 8 & 5 & 6 & 5 \\
\hline Repolho & 11 & 8 & 12 & 8 & 8 & 10 \\
\hline Almeiräo & 6 & 6 & 8 & 6 & 5 & 8 \\
\hline Cenoura & 1 & 12 & 12 & 1 & 7 & 7 \\
\hline Brócoli & 10 & 10 & 17 & 8 & 9 & 14 \\
\hline Tomate & 9 & 17 & 12 & 9 & 13 & 13 \\
\hline \multirow[t]{3}{*}{ Média } & 6,5 & 8,6 & 11,1 & 6,0 & 7,4 & 9,8 \\
\hline & \multicolumn{3}{|c|}{ Atrazina $1,8 \mathrm{~kg} / \mathrm{ha}$} & \multicolumn{3}{|c|}{ Atrazina $3,2 \mathrm{~kg} / \mathrm{ha}$} \\
\hline & ----- & - dias -- & ----1 & . - - - & dias & - - - \\
\hline Couve flor & 5 & 6 & 8 & 5 & 6 & 8 \\
\hline Alface & 5 & 5 & 11 & 6 & 6 & 8 \\
\hline Rúcula & 6 & 6 & 8 & 6 & 6 & 9 \\
\hline Repolho & 12 & 8 & 12 & 8 & 8 & 9 \\
\hline Almeirão & 6 & 6 & 8 & 6 & 6 & 6 \\
\hline Cenoura & 1 & 7 & 8 & 1 & 5 & 5 \\
\hline Brócoli & 10 & 10 & 14 & 10 & 10 & 14 \\
\hline Tomate & 8 & 8 & 13 & 8 & 9 & 13 \\
\hline Média & 6,6 & 7,0 & 10,3 & 6,3 & 7,0 & 9,0 \\
\hline
\end{tabular}



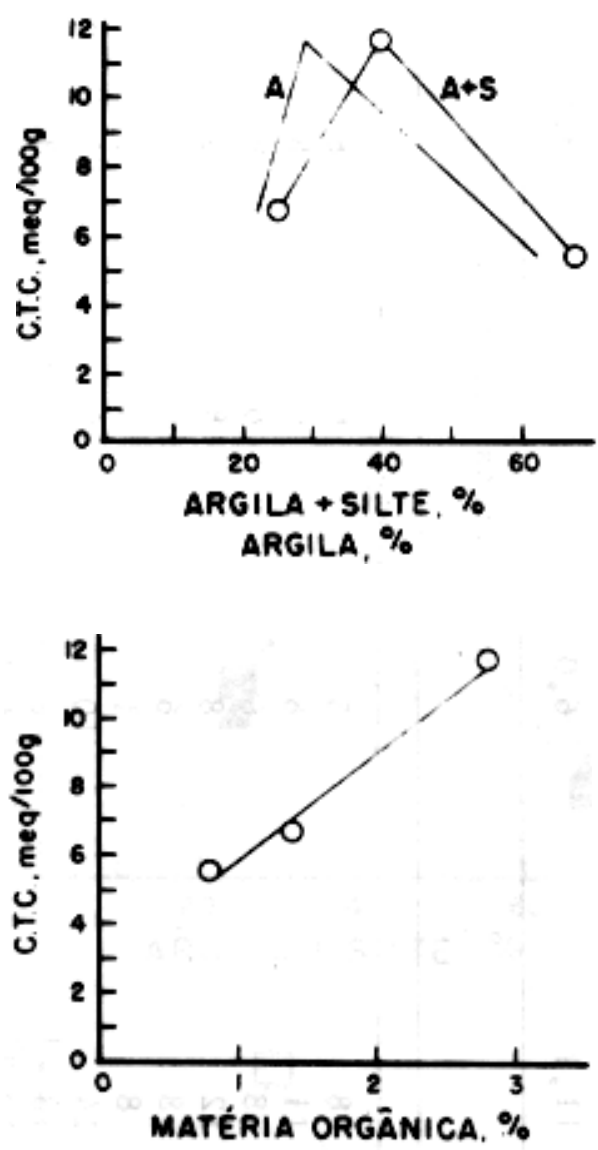

Figur a 2. Re la ção en tre a ca pa ci da de de troca catiônica(CTC) e os teor es de argila (A, \%), argi la ma is silte $(\mathrm{A}+\mathrm{S}, \%)$ e matéria orgânica (MO, \%) dos três tipos de solos us ad os no ensaio com he rb ic id as .

O tempo de sobrevivência das hortaliças também foi afetado pelo pH (Figura 3). Houve menor adsorção dos herbicidas em $\mathrm{pH}$ mais elevado, dentro da faixa de acidez estudada, o que e concordante com outros autores $(5,10,15,17,18)$. No entanto, há citação na literatura (18) que a adsorção não está linearmente correlacionada ao $\mathrm{pH}$ ao se considerar toda a faixa de acidez do solo.

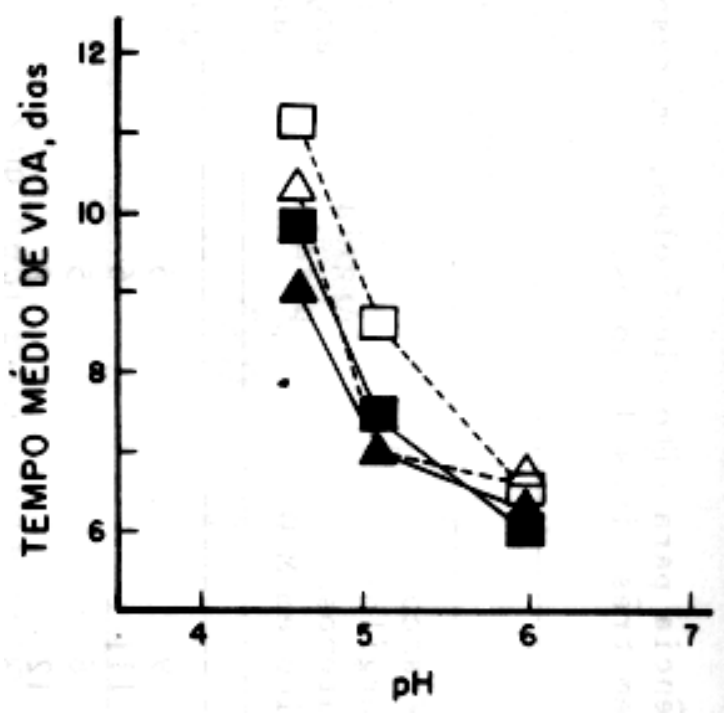

Figu ra 3. Tempo médio de vida de oi to ho rtal iças (dias) para duas doses de dois he rbicidas, em solos com diferentes valores de $\mathrm{pH}$ em ag ua .
Os resultados obtidos não invalidam o efeito da textura na adsorção e na dosagem dos herbicidas.Devido à rápida decomposição da matéria orgânica em solos tropicais, Lepsch et al. (9) encontraram alta correlação entre os teores de mate ria orgânica e os teores de argila mais silte, nas camadas de $0-20 \mathrm{~cm}$, em solos agriculturáveis paulistas. Um fator de complicação para o correto correlacionamento do 
teor de matéria orgânica do solo com a dose do produto, esta na origem e no grau de decomposição do material. Raij (12) obteve em solos paul istas valores de atividade catiônica da matéria orgânica variando de 135 a 488 meq/100g. Há ainda evidências na literatura(15), pelo menos em solos orgânicos de região temperada de mesma CTC, que a origem do material atuaria diferentemente na adsorção dos herbicidas do grupo químico das s-triazinas.

A separação dos efeitos da CTC, da matéria orgânica e do $\mathrm{pH}$ não foi possível neste trabalho em virtude do pequeno número de solos envolvidos na experimentação e por estarem essas características correlacionadas entre si. Os resultados obtidos levam a ponderar que os conhecimentos sobre adsorção possam ser de difícil generalização nas nossas condições edafo-climáticas. Diante dessas considerações é possível notar a necessidade da obtenção de maior numero de informações sobre a adsorção dos herbicidas nas condições tropicais, o que é de importância fundamental para a prática do uso desses produtos.

\section{LITERATURA CITADA}

1. Ashton, F.M. \& Crafts, A. S. Mode of action of herbicides. USA. John Witey \& Sons 1973. 504p.

2. Birkeland, P.W. Pedology, wea thering and geomorphologi = cal research. New York, of ford University Press, 1979, 285p.

3. Camargo, O.A. de; Moniz, A.C.; Jorge, J.A. \& Valadares, J.M.A.S. Mêtodos de anälise química, mineralógica e física de solos do Instituto Agronômico de Campinas. Campinas, Instituto Agronômico, 1986. 94p. (Boletim Tếcnico, 106).

4. Gelmini, G.A. Herbicidas - Indicaçōes Básicas - Campinas, Coordenadoria de Assistência Técnica Integral, 1985. 251p.

5. Harris, C.I. \& Warren, G.F. Ad sorption and desorption o $\bar{f}$ herbicides by soil. Weeds, 12 (2) : 120-126, 1964.

6. Herbicide Handbook of the Weed Science Society of America. 49 Ed., Illinois, Champaign, 1979. 479p.

7. Hertwig, $K$. von. Manual de herbicidas desfolhantes, des secantes, fitorreguladores $\bar{e}$ bio-estimulantes. São Pau10, Ed. Agronômica Ceres, 1983. 670p.

8. Hil1, G.D.; McGahen, J.W.; Baker, H.M.; Finnerty, D. W. \& Bingeman, C.W. The fate of substituted urea herbici des in agricultural soils. Agron. J., 47 : 93-104, 1955.

9. Lepsch, I.F.; Silva, N.M. da \& Espironelo, A. Relação entre matéria orgânica e textura de solos sob cultivo de algodão e cana-de-açúcar, no Estado de São Paulo. Bra gantia, Campinas, 41: 231= 236,1982 .

10. Liu, L.C.; Cibes-Viadē, H. \& K-o, F.K.S. Adsorption of ametryne and diuron by soils. Weed Science, 18 (4) : 470-474, 1970.

11. Lopes, A.S. Solos sob "cerrado": características, propriedades e manejo. Piracicaba, Instituto de Potassa e Fosfato e Instituto Inter nacional de Potassa, 1983. $162 \mathrm{p}$. 
12. Raij, B. van. Capacidade de troca das fraçôes orgânicas e minerais dos solos. Bragantia, 28: 85-112, 1969.

13. Sanchez, P.A. Properties and management of soils in the tropics. New York, John Wileyand Sons, 1976. 618p.

14. Silva, J.F.; Da Silva, J.F.; Da Silva, R.F. \& Condê,, S. R. Lixiviação e inativação do metribuzin em dois tipos de solos. Planta Daninha, IV (2) : 78-82, 1981 .

15. Talbert, E.R. \& Fletchall, O.H. The adsorption of some striazines in soils. Weeds, $13(1)$ : 46-52, 1965.
16. Verdade, F.C. Influência da ma têria orgânica na capacida de de troca de cátions do solo. Bragantia, 15: 3542, 1956.

17. Upchurch, R.P. \& Mason, D. D. The influence of soil organic matter on the phytotoxi city of herbicides. Weeds, 10(1): $9-14,1962$.

18. Weber, J.B.; Weed, S.B. \& Ward, T.M. Adsorption of some s-triazines by soil organic matter. Weed Scien ce, $17(4)$ : 417-421, 1969. 